\title{
Bir Gazetecinin ‘Muhibbân-ı Kütüp’ Olarak Portresi ve S. M. Tevfik Kütüphanesi
}

\section{Portrait of a Journalist as 'Muhibbân-ı Kütüp’ and S. M. Tawfiq Library}

\section{Ekrem Saltık}

\section{$\ddot{O} z$}

Osmanlı kitap ve kütüphane kültürü, söz konusu olan II. Meşrutiyet Dönemi olduğunda, genellikle Ali Emîrî Efendi gibi sembol isimlerin öne çıktığg, ama "Mecânîn-i Kütüp" ya da "Muhibbân-ı Kütüp" gibi sıfatların yaklştırıldı̆̆ı birçoğu bilinmeyen çok sayıda aktörün katkıda bulunduğu bir sahadır. Modern literatürde "kitap delisi" anlamında kullanılan "bibliyoman" ve "kitap sever" anlamındaki "bibliyofil" terimlerine karşılık gelen bu sıfatlarla anılabilecek bazı isimler, kitap ve kütüphane merkezli yaşamlarlyla Osmanlı kültür tarihine mütevazi katkılarda bulunmuştur. Kitaplarla kurdukları ilişkileri, Muhibbân-ı Kütüplük seviyesinde olan isimlerin bazlları, kitap peşinde geçen yaşamlarıyla, tarihe mâl olmuş ama fiziki varlıkları zamanla efsaneleşmiş hale gelen bazı kitapları tesadüfen de olsa bularak yeniden hayata döndürmüşür. Bilinçli bir kitapseverlik ve koleksiyonerliğe karşılık gelen bir ifade olan Muhibbân-ı Kütüp sıfatını hak eden bu isimlerin bazıları, sahip oldukları çoklu dil yeteneği ve uzak coğrafyalara seyahat imkânlarıly, kitaplara vakfettikleri yaşamlarının zengin birer özeti olan irili ufakl kütüphaneler kurmuştur. Bu kişi ve kütüphanelerin bazıları biliniyorsa da bazıları farklı sebeplerle çeşitli dönemlerde ya unutulmuş ya da hiç fark edilmemiştir. Bu zeminde kendi kuşağının en meşhur kitap uzmanlarından biri ve oldukça zengin bir kişisel kütüphane sahibi olan bir gazeteciyi merkeze alacak olan bu makale, Osmanlı basın tarihine Sebîlürreşâd dergisindeki seyahat yazılarıyla dâhil olan S. M. Tevfik'in bilinmeyen bir yönünü ve sahip olduğu zengin kütüphanesini gündeme getirecektir. II. Meşrutiyet Döneminde gerek kitap uzmanliğl ve gerekse kütüphanesiyle çok uluslu bir üne sahip olmasına rağmen şimdilerde adı unutulmuş olan S. M. Tevfik'in hem gazetecilik hem de kitap koleksiyonerliği anlamında aksiyoner olan yaşamının kitap ve kütüphane kültürüne katkısı bağlamında ele alınmasıyla, Türk kitap ve kütüphane tarihinin kayıp halkalarından birinin daha gün yüzüne çıkarılması umulmaktadır.

Anahtar Sözcükler: S. M. Tevfik; Seyyid Muhammed Tevfik; muhibbân-ı kütüp; bibliyofil; kitap koleksiyonerleri; kitap uzmanlarl; İstanbul kütüphaneleri; özel kütüphaneler.

\begin{abstract}
The bibliophile culture is the Ottoman Empire is usually associated with the names such as Ali Emîrî Efendi as an iconic figure in The Second Constitution Period. Yet, the attributions such a Mecânîn-i Kütüp [Those who are madly in love with the books] or, "Muhibbân-ı Kütüp"
\end{abstract}

\footnotetext{
* Dr. Öğr. Üyesi, İstinye Üniversitesi Sosyoloji Bölümü. E-posta: esaltik@istinye.edu.tr Assistant Prof., Istinye University Department of Sociology, Turkey
} 
[Book Lovers], can be used to describe a great many cultural activists that are generally unknown in academic circles. In modern literature, the figures who can be explained by the term's bibliophile and biblioman has been recognized and appreciated moderately for the role they have played in the prospering of book and library culture. The ones whose intimate relationship with the books have led to their financial ruins and eternal appreciation from history. Only a handful of such figures have got the opportunity to be revived from the annals of history due to recent scholarships. Many of these respectable figures have enriched their libraries and private book collections with extraordinary zest and determination, acquiring vast linguistic knowledge and undertaking extensive voyages in the old world. Thus, they earned the right to be called bibliophile. Most of these scholars, their heroic endeavors, and precious collections have joined the annals of history, except for a handful of few. This current paper is an attempt to revive and recognize one of the greatest bibliophiles of the period, S. M. Tawfiq whose contribution to Ottoman publication in Sebîlürreşâd journal as a travel writer had earned him fame in publication circles, yet, his other contribution to book culture, namely his book collection, has received insufficient attention so far. This current paper is an attempt to pay the due tribute to the man whose expertise on books, along with his insatiable love of knowledge, his journalism, and his outstanding book collection had contributed immensely to the prospering of book culture in The Second Constitution Period. This paper hopes to provide S. M. Tawfiq with the recognition that he certainly deserved.

Keywords: S. M. Tawfiq, Sayyid Muhammad Tawfiq, muhibbân-ı kütüp, bibliophile, book collectors, book experts, İstanbul libraries, private library.

\section{Giriş}

Osmanlı kitap ve kütüphane kültürünün önemli isimleri arasında yer alan ve daha çok Millet (yazma eser) Kütüphanesinin kurucusu olarak bilinen Ali Emîrî Efendi, çok zaman bir Mecânîn-i Kütüp olarak da anılır. Ama onu, literatürde "kitap delisi" anlamında kullanılan bu sıfatı taşıyan ortalama bir koleksiyonerden ayıran özelliği, nadirat dâhil, fiziki ve estetik detaylarına vâkıf olduğu kitaplara ilgisinin, bilimsel ve edebi açılardan içeriklerine nüfuz edebilecek entelektüel bir boyut da taşıyor olmasıdır. ${ }^{1}$ Dolayısıyla modern literatürdeki ifadeyle, -kitaplar konusunda bilinçsiz bir düşkünlüğe karş1lık gelen- bir bibliyoman değil, aksine bilinçli bir kitapseverlik ve koleksiyonerliğin ifadesi olan- bir bibliyofil olarak anılması gereken Ali Emîrî Efendi, eskilerin "kitap sever" anlamında Muhibbân-ı Kütüp dediği bir geleneğin parçasıdır. Coğrafi sınır tanımadan, fedakârca ve tutkuyla topladığı binlerce ciltlik zengin kitap koleksiyonunu Millet Kütüphanesine vakfederek, kitap ve kütüphane tarihine büyük bir katkı sağlamıştır. Ali Emîrî Efendi'nin Türk kültür tarihine bir başka katkısı, nadir kitap toplarken tesadüfen bulduğu ve içeriği 20. yüzyılın başına kadar sadece nakil yoluyla bilinen Dîvânü Lugāti't-Türk adlı eseri kültür tarihine yeniden kazandırmış olmasıdır. Muhibbân-1 Kütüp geleneğinin bu önemli temsilcisi, bir şekilde asırlardır elden ele dolaşırken, şirazeleri dağılmış, forma ve sayfaları birbirine karışmış hale gelen söz konusu kitabı, birkaç altın ödeyerek satın almış, nihayetinde onu bir bibliyofil yapan uzmanlığı sayesinde, temelde

\footnotetext{
${ }^{1}$ Muhibbân-ı Kütüp ve Mecânîn-i Kütüp sıfatlarını taşıyan insanlar arsındaki nüanslar, kitap ve kitabın tarihiyle ilgili Türkçe literatürdeki öncü çalışmalardan biri olan "Kitap" adlı eserinde, kitap meraklılarını iki guruba ayıran Necip Âsım tarafından oldukça sade ve net bir şekilde tarif edilir. (Yazıksız, 2020: s. 119-133)
} 
bir Türk dil sözlüğü olan bu nadir eserin, aslında Kâşgarlı Mahmud tarafindan - 11. yüzyılda yazılmış olan Dîvânü Lugāti 't-Türk olduğunun ayrımına varmıştır (Ülkütaşır, 1946, s. 56-82).

Seyyid Mehmed Şeref Efendi'nin oğlu olarak Diyarbakır'da dünyaya gelmiş olan Ali Emîrî Efendi, Türkçe ve Kürtçe'nin yanı sıra Arapça ve Farsça da bilmektedir (Tayşi, 1989). Tarihe geçmesini sağlayan ve aslında bizzat kendisinin, tarihe karışmalarını engellediği kitaplar konusundaki uzmanlığı, hiç şüphesiz birden fazla dil biliyor olmasından da beslenmiştir. Nihayet Ali Emîrî Efendi'nin kitaplar ve kütüphaneler konusundaki çoklu dil hâkimiyetinin de katkısıyla, Muhibbân-1 Kütüp geleneğinin önemli bir temsilcisi olarak anılmasını sağlayacak kitap toplama faaliyetini yoğun olarak gerçekleştirdiği yıllar, II. Meşrutiyet Dönemine karşılık gelmektedir.

\section{Meşrutiyet Dönemi Kitap ve Kitap Okuma Kültürüne Bir Nazar}

II. Meşrutiyet Dönemi, siyasi, askeri ve ekonomik olduğu kadar kültür tarihi açısından da çeşitli araştırmalarla "didik didik" edilmesine rağmen, söz konusu olan, dönemin kitap ve kütüphane kültürü olduğunda, çoğunlukla yazma kitap-basma kitap yahut okuma-yazma meseleleri ekseninde fiziki detaylar ve niceliğe dair analizlerle yetinilen bir dönemdir. Herhangi bir dönemin kitap ve kütüphane kültürüne dair değerlendirme yapabilmek için çeşitli resmi ve istatistiksel kayıtlardan faydalanmak metodolojik olarak doğru ve işlevselse de örneğin o sırada dolaşımda olan kitapların muhtevası ve okuyucu profil/ler/ine dair kapsayıcı analizler yapmak söz konusu olduğunda tek başına yeterli olmayacaktır. Nitekim bir dönemde, Mecânîn-i Kütüp sıfatının dışında kalan yaygın okuyucu profil/ler/inin anlaşılması, aynı dönemde Muhibbân-ı Kütüp geleneğinin gereği olarak, yaşamlarını hem içerikleri hem de sanatsal özellikleriyle nitelikli ve nadir olan kitapları toplamaya adamış insanların, aslında nasıl bir sosyokültürel atmosferde "nefes almaya" çalıştıklarını anlamak adına oldukça önemlidir. Bu bağlamda, II. Meşrutiyet Dönemi, resmi kayıtlar ve istatistikler dışında, kitap ve kütüphane kültürüne dair derinlikli analizler yapılmasına olanak sağlayacak diğer veri kaynakları arasında bulunan gazete, dergi ve hatıratın her geçen gün daha da arttı̆̆ Dolayısıyla, II. Abdülhamid'in istibdat yıllarının ardından - kısa süreli de olsa - yaygın bir umut vaat eden "özgürlük" atmosferinde çok sesli ve renkli hale gelen Osmanlı basınına dâhil olan yüzlerce gazete ve dergi, dönemin kitap ve kütüphane kültürünü farklı boyutlarıyla analiz etmeyi mümkün kılacak içerikleriyle de dolaşıma girmiş̧tir (Kabacalı, 2000, s. 133).

II. Meşrutiyet yıllarında yayın hayatına başlayarak dönemin Mecânîn-i Kütüp ve Muhibbân-1 Kütüp geleneğinin dışında kalan okuyucu profilleri ve yaygın dolaşımdaki kitapların muhtevasına dair fikir verebilecek süreli yayınlar arasında Sebîlürreşâd dergisi de bulunmaktadır. Sebîlürreşâd'ın ilk günden itibaren büyük ilgiyle karşılanan sayıları, zengin içeriği ve yazar çeşitliliğinin de etkisiyle Rusya'dan Orta Asya'ya, Güney Asya'dan Uzakdoğu'ya kadar geniş bir coğrafyaya ulaşmıştır (Efe, 2009). Bu geniş coğrafyayla doğru orantılı olarak çeşitlenen bir okuyucu kitlesine hitap eden Sebîlürreşâd'ın sayfaları, yukarıda bahsedilen, bir döneme ait yaygın okuyucu profili ve dolaşımda olan kitapların muhtevası konusu bağlamında, II. Meşrutiyet Dönemiyle ilgili farklı ve derinlikli değerlendirmeler yapmak adına çarpıcı içerikler taşımaktadır. Derginin çeşitli tarihlerdeki sayfalarına yansıyan okuyucu mektupları ve editoryal değerlendirmelerde, dönemin kitap ve okuma kültürü bağlamında sık sık tekrar edilen bazı şikâyetler oldukça dikkat çekicidir. Bu şikâyetleri 
karakterize edecek bir olay, derginin Ekim 1912 tarihli bir nüshasına yansımış, Sebîlürreşâd'ın idarehanesini ziyaret eden bir zâbit, yeni basılan ciddi eserlerin neler olduğunu öğrenmek üzere girdiği bir kitapçıya soru sorduğunda, derin bir iç çeken kitapçı, "A efendim, ciddî eserleri kim arıyor ki yazan, basan bulunsun?" cevabını vermiştir. Devamında benzer şikâyetlerin derginin birçok sayısında tekrar edildiği üzere, kitapçıların o sırada, işlevi sadece "ahlâk-1 umûmiyyeyi berbâd etmek" olan ve "kapaklarında açık seçik resimler bulunan" kitaplar satarak para kazanabildiğini söyleyen kitapçı, "ciddi kitaplar" arayan yahut okuyan bir okuyucu kitlesi kalmadığından bahsetmiştir (Sebîlürreşâd, "Sebîlürreşâd”, s. 92).

Sebîlürreşâd'ın sayfalarına yansıyan ve kitabın temel, taşınabilir yaygın bir kültür aktarım nesnesi olarak, birey üzerindeki egemenliğini ilan etmesinden itibaren tüm çağlarına nüfuz eden bir başka işlevinin doğal sonuçlarına işaret eden bu durum, elbette tüm modern toplumların yaygın gerçeklerinden biridir. Nitelikli kitap peşinde bir okuyucu, kitapçı ve nihayet Muhibbân-1 Kütüp'den olmanın, ayrıca hangi "görünmeyen duvarları" zorlamayı gerektirdiğini "anlamak" adına çarpıcı olan bu örneği nakletmiş olan Sebîlürreşâd, kitap ve okuma kültürü adına toplumsal eleştirilerde bulunduğu çeşitli sayılarıyla "Osmanlı hey'et-i ictimâiyyesi okuyor mu?” sorusuna cevap da aramıştır. Bu bağlamda gerek okuyucuları gerekse yazar kadrosunda, "mecnunluktan" "muhibliğe", kitaplarla çeşitli ilgi seviyelerinde hemhal olan çok sayıda insan bulunan Sebîlürreşâd' da yazan Ispartalı Hakkı'ya göre, "her şeyin ilim, ders, yazı ve kitap olduğu" 20. yüzyılın ilk çeyreğinde, "dünya, milletler, sınıflar ve ferdler" okumaktadır. Okumanın "hayatın bütün işlerini kucaklayan" başlı başına "bir iş" haline geldiği bu dönemde, "Osmanlı hamuru içindeki en büyük ve en koyu parça olan Müslüman Türkler" için aynı şeyin söz konusu olmadığını ileri süren yazar, bizzat yaptı̆̆ı gözlemlerden hareketle, vasata egemen olan okuma alışkanlığının, "dudak keyfi cıgara dumanlatan çocuklar gibi yarım yamalak" olduğu tespitinde bulunmuştur. Ona göre, "başka milletlerde okuma inâyetiyle terzinin, çulhanın, demircinin, dülgerin, çiftçinin, bahçıvanın gazeteleri, kitapları bulunurken" Müslüman Türklerde "okumak - ve dolayısıyla kitapsever olmak - afyon kullanma gibi tabîattan dışarı, sıkıc1, yorucu, öldürücü bir şey olmuş, azlığın ve havâssın pehlivanlık işi olup kalmışs” durumdadır (Ispartalı Hakk1, 1919, s. 376).

Bir dönem ve toplumsal gerçeklikle ilgili olarak elbette sadece bir kesit verebilecek olan bu şikâyet, ilginç bir şekilde benzer eleştirileri kendi toplumu için yapan Jonh Ruskin'in 1864 yılında yaptığı bir konferans konuşmasındaki sözlerini çağrıştırmaktadır. Zira çağının önemli toplum ve sanat eleştirmenlerinden olan Ruskin de daha sonra Susam ve Zambaklar kitabında derlenecek olan konferans konuşmalarından birinde, "Millet olarak kitapları hor görüyoruz." diyerek, şu ironik tespiti yapmaktadır; "Herhangi bir kimse kütüphanesi için biraz fazlaca para harcasa ona deli, 'kitap delisi' dersiniz. Halbuki pek çok kimse her gün parasını pulunu atları uğruna harciyor da onlara 'at delisi' demiyorsunuz." (2016, s. 60). Kitap okuma, kitap sahibi olma ve nihayet kütüphaneler konusunda, Susam ve Zambaklar' dan sonra Sebîlürreşâd' da da yer alan ve hemen hemen birbirinin tekrarı gibi duran bu eleştiriler, farklı çağlarda farklı toplumların kitap okuma eğilimlerine dair kesitler sundukları için sosyolojik bir analizin temel dayanağı olamayacaksalar da en nihayetinde "kitap muhibbi" olmanın her toplumda ve çağda aynı zamanda ekonomik ve sosyal zorlukları göze almak anlamına geldiğini göstermektedir. Ispartalı Hakkı'nın bahsini ettiği okuma alışkanlığı bağlamında, bir dönemin kitap ve kütüphane kültürüne dair farklı görünmeleri ortaya koyan Sebîlürreşâd dergisindeki benzer 
örnekler de Muhibbân-1 Kütüp geleneğine dâhil olmanın, - hele hele siyasi ve ekonomik açıdan büyük dönüşümlerin yaşandığ d dönemlerde - mensup olunan toplumun geleceğine dair entelektüel sorumluluk duyan bireylerin omzuna yüklediği - hiç de hesaba katılmayan ağırlığa işaret ettiği için oldukça önemlidir.

\section{Gazete, Dergi, Kitap ve Kitapçılar Arasında Bir Muharrir}

Bu zeminde dönemin kültürel, ekonomik, teknik ve coğrafi koşullarında ayrıca zorlukları olan bir tercih yaparak dâhil olunan Muhibbân-1 Kütüp geleneğinin II. Meşrutiyet Dönemi özelindeki en önemli siması olduğunu tekrarla, Ali Emîrî Efendi'nin, o dönemde bu geleneğin tek temsilcisi olduğunu söylemek elbette yanlış olacaktır. Zira dönemin okuma ve kitap kültürüyle ilgili farklı görünümlere dair izler bulmak üzere bu çalışmada çeşitli sayılarından alıntılar yapılan Sebîlürreşâd'ın ele aldığı konular ve yazarlarının kitaplarla olan ilişkisine bakıldığında, bu derginin bile, bizzat kurumsal kişiliğiyle Muhibbân-1 Kütüp sıfatını hak ettiği görülecektir. Bâbıâlî Caddesi'ndeki merkezinde hususi bir kütüphane kurduğu da anlaşılan Sebîlürreşâd, bu kütüphanesiyle, okuyucuların kitap siparişlerini kabul ve temin eden bir kitapç1lık faaliyeti yürütmüştür. (“Sebîlürreşâd İdare ve Kütüphanesi”, 1913, s.88)

Kurumsal kimliği ve bu kimliğin parçası olan yazarlarıyla birlikte düşünüldüğünde Sebîlürreşâd dergisinin II. Meşrutiyet Döneminde kitap ve kütüphane kültürüne katkıda bulunan bir kuşağın parçası olan çeşitli isimleri bir araya getirdiği de anlaşılmaktadır. Bu bağlamda Muhibbân-1 Kütüp sıfatını hak edecek şekilde geçirdikleri yaşamlarının bir bölümünde Sebîlürreşâd kadrosunda yer alıp, bir şekilde Türk kitap ve kütüphane tarihinin kayıp halkaları arasına karıştıkları için adları unutulmuş ya da hiç bilinmeyen isimler arasında, çoğunlukla dergideki seyahat yazılarıyla tanınan S. M. Tevfik de bulunmaktadır. Sebîlürreşâd' daki yazılarında, S. M. Tevfik [س. م. توفيق] ve S. M. T. . س. م. ت.] imzaları kullanmış olan Tevfik Bey'in yaşamını, gerçekte kim olduğunu ortaya koyacak şekilde, tüm boyutlarıyla ele alan kapsayıcı bir çalışma yapılmamıştır. ${ }^{2}$

19. Yüzyılın son çeyreğinde muhtemelen 1880'li yılların hemen başında İsfahanlı bir baba ve Iraklı bir annenin çocuğu olarak Hindistan'da doğup, İstanbul'da büyüyen ve İranlı bir babanın çocuğu olsa da annesinden dolayı Osmanlı tebaasından olan S. M. Tevfik'in tam adı, 1912 yılında kadrosuna dâhil olduğu Sebîlürreşâd dergisinde "[Basralı] Seyyid Muhammed Tevfik ” olarak verilmiştir. (“Sebîlürreşâd'ın Yeni ve Mühim Bir Teşebbüsü “, 1912, s. 334-335) Babasının kökeni nedeniyle Farsça literatürde genellikle Seyyid Muhammed Tevfîk Hemedanî olarak anılan Tevfik Bey, 1900'lerin hemen başında İran'da aktif hale gelen meşrutiyet hareketinin (1905-1907) önemli simalarından biri olarak Yakın Çağ İran tarihi açısından da önemli bir gazetecidir. 20. yüzyılın başında, İran'daki meşrutiyet hareketine yurt dışından en etkili ve güçlü desteği vermiş İstanbul'daki İran diasporasına mensup olan Tevfik Bey, bu dönemde İstanbul'da yayımlanan Şems ve Surûş gibi Farsça gazetelerin yazar ve editör kadrosunda yer almıştır (Browne, 1914). Nihayet bu gazetelerden sonra "ser muharrir" ve "müdür-ü âmir" olarak uzun yıllar yönettiği bir başka Farsça gazete olan Haver gazetesindeki rolü ve yayın politikalarıyla, II. Meşrutiyet Dönemi İran matbuatının en önemli isimlerinden

\footnotetext{
${ }^{2}$ S.M. Tevfik'in yaşamını Osmanlı basın tarihi ve yakın çağ İran tarihindeki rolleri bağlamında kapsayıcı bir şekilde ele alan henüz tamamlanmış bir çalışma için bak. Ekrem Saltık, "Sebîlürreşâd'ın Hindistan Muhâbiri S.M. Tevfik'in 'Meçhul' Biyografisine Dair"
} 
biri olmuştur. Şehbâl, Cerîde-i Sûfiyye ve el-Hilâl gibi dönemin diğer gazete ve dergilerinde de yazılar yazmış olan Tevfik Bey, Sebîlürreşâd dergisi kadrosuna dâhil olmasından önce, İstanbul'daki İran Okulu'nun (Debistân-ı İraniyân) idareciliğini de yapmıştır (Sasanî, 2006, s. 81-83; Bashari, 2017, s. 23)

Bu kısa özgeçmişten de anlaşılacağı üzere hem Osmanlı tarihi hem de İran tarihi açısından değerli, oldukça üretken ve aktif bir gazeteci olan Seyyid Muhammed Tevfîk Hemedanî'yi bu makalenin de konusu bağlamında - çağdaşı olan benzer profillerden ayıran bir başka özelliği, yaşamının büyük bir bölümünü geçirdiği İstanbul'daki zengin kütüphanesi ve kitaplar konusundaki uzmanlığıdır. İstanbul'da yaşayan İranlılar da dâhil olmak üzere, II. Meşrutiyet Döneminde yaşamış Muhibbân-1 Kütüp sıfatını taşıyan isimler arasında olmasını sağlayacak şekilde, kitaplara adanmış yaşamıyla da ele alınması gereken Tevfik Bey, Mirza Habib İsfehanî’den sonra İran tarihinin en önemli kitap koleksiyoneri olarak da gösterilir (Bashari, 2017, s. 55).

Tevfik Bey’i kitap ve kütüphane tarihiyle ilgili bu kategorizasyonda böylesi bir tepe noktaya yerleştiren ve İstanbul merkezli Farsça matbuat tarihindeki rolü bağlamında hakkındaki tek geniş kapsamlı çalışmayı yapmış olan Bashari'ye göre, Tevfik Bey'in kitap koleksiyoneri kimliği, Osmanlı sarayı tarafından da bilinen ve devlet bürokrasiyle yakın ilişkiler içerisinde olabilmesini sağlayan meziyetlerinden biridir (2017, s. 64). Bu meziyetiyle İstanbul sınırlarını aşan bir üne sahip olduğunu gösteren bir olay, Hâzikulmelik adlı bir doktorun - muhtemelen 1910-1912 y1lları arasında gerçekleştirdiği - bir ziyaret sırasında yaşanmış, Tevfik Bey, bu meşhur Hintli doktorun İstanbul'daki kütüphane ve kitapçılarda dolaşırken mihmandarlığını yapmakla kalmayıp, Yunan tıbbına dair bir el yazmasını istinsah ettirmesine yardımcı da olmuştur (S. M. Tevfik, 21 Mayıs 1914, s. 205).

Tevfik Bey’in kitaplarla olan ilişkisinin, sınırları aşan bir kitapçı ve kütüphane ağına dâhil olmasını sağlayan bir uzmanlık seviyesinde olduğunu ve ticari boyutlar da taşıdığını düşündüren bir başka olay, 1909 yılında İstanbul'da gerçekleşen bir yangın sırasında yaşanmıştır. Bu bağlamda ortalama bir insanın aylık giderinin beş lira olduğu bir dönemde, sahip oldukları beş yüz lira değerindeki on ciltten oluşan bir takım kitabı satmak isteyen birkaç İranl1, İstanbul'a geldiklerinde, binlerce kilometre uzaktan beraberlerinde getirdikleri bu nadir eserleri, fiyat biçip alıcı bulması için Tevfik Bey’e emanet etmiştir. Ancak tek amaçları, söz konusu kitapları satmak olan İranlıların küçük bir servete karşılık gelen emanetlerini Tevfik Bey'e vermelerinden hemen sonra Fatih'te çıkan bir yangın, Tevfik Bey'in eviyle birlikte kütüphanesinin de yanmasıyla sonuçlanmıştır. Yangınla birlikte Tevfik Bey’e emanet ettikleri kitaplarının da yanıp kül olduğundan emin olmalarına rağmen, bir süre sonra yangının harabeye döndürdüğü semte ve Tevfik Bey'in yanına gittiklerinde, makbuzu dâhi olmayan değerli kitaplarını iade alabilmenin şaşkınlık ve sevincini yaşayan İranlıların bu ilginç hatırası, Tevfik Bey’in kitaplar ve kitap sahipliği konusundaki faaliyetlerinin ticari hırslardan arınmış, manevi ve estetik duygularıyla şekillenen hassasiyetler taşıdığını düşündürmektedir. Nitekim Tevfik Bey, kitapları iade ederken, kendi evi dâhil onlarca evin yanmasıyla sonuçlanan yangın sırasında "denizleri aşarak" getirilen ama "sudan kurtulduktan sonra, yangından da kurtulamazlarsa" sahiplerini büyük sıkıntıya düşürecek olan söz konusu kitapları kurtarmak için özellikle çaba sarf ettiğini ifade etmiştir (Bashari, 2017, s. 60-62). 


\section{Kitap, Kitapçı ve Kütüphane Peşinde Bir Seyahat}

Evinin de harabeye döndüğü bir yangın sırasında, sahip olduğu kitapların büyük bir kısmını kaybeden Seyyid Muhammed Tevfîk Hemedanî’nin meşhur kütüphanesi, Bashari’nin tarifine göre, iki ayrı dönemden oluşmaktadır (2017, s. 56). Bu durumda 1909 tarihindeki büyük yangından sonra yeniden kitap toplama faaliyetlerine giriştiği anlaşılan Tevfik Bey’in ikinci kütüphanesini kurmak üzere yeniden kitap toplamaya başladığı dönem, aynı zamanda Osmanlı basın tarihine dâhil olduğu Sebîlürreşâd dergisindeki yıllarına karşılık gelmektedir. Dolayısıyla bir sonraki bölümde detaylandırılacağı üzere - ikinci - kütüphanesine ait fihristte, sahip olduğu kitapların her birini bizzat basıldıkları ülke ve şehirlerden getir(t)mek için her türlü maddi ve manevi fedakârlığı gösterdiğini anlatan Tevfik Bey’in bahsini ettiği fedakârlıkların bir kısmını, Sebîlürreşâd dergisi muhabiri olarak gittiği Güney Asya seyahatiyle eş zamanlı olarak gerçekleştirdiği tahmin edilebilir.

Tevfik Bey, söz konusu seyahatini uzak ve farklı coğrafyalarda yaşayan Müslümanlara ulaşarak, buralardaki Müslümanların birbirlerinden haberdar olmalarını sağlamak üzere Hindistan, Türkistan, Türkmenistan, Buhârâ, Çin, Romanya ve Bulgaristan gibi memleketlere temsilci gönderme kararı alan Sebîlürreşâd dergisinin ("Sebîlürreşâd'ın Yeni ve Mühim Bir Teşebbüsü”, 1912, s. 334-335) Hindistan muhabiri olarak gerçekleştirmiştir. 1912 yılının Temmuz ayı ortalarında İstanbul'dan ayrıldıktan sonra Anadolu'dan Güney Asya'ya uzanan geniş coğrafyada, yol güzergâhı üzerinde bulunan çok sayıda yerleşim yerine uğrayarak, 1913 yılı Temmuz ayında Hindistan'a ulaşan Tevfik Bey'in yolculuğunu, aynı zamanda bir kitap ve kütüphane keşif yolculuğu olarak okumak da mümkündür. Zira yaklaşık iki yıl süren seyahati sırasında kaleme aldığı mektupların satır aralarında, kendisiyle eş zamanlı olarak dünyanın çeşitli ülkelerine seyahatler gerçekleştiren diğer Sebîlürreşâd muhabirleri gibi Tevfik Bey de gittiği her yerde kitapçılar ve kütüphanelerde kitap aradığına işaret eden çeşitli anekdotlara yer vermiştir. Bu noktada, Tevfik Bey'in de dâhil olduğu kurumsal kimliğiyle Sebîlürreşâd yazarlarının Muhibbân-1 Kütüp sıfatını hak edecek şekilde kitaplara duydukları ilginin seyahatlerindeki boyutuna dair bir örneği, dergide yazıları yayınlanan bir başka isim olan Hâris bin Hümâm vermektedir. Gittiği her yerde kitapçılara uğramayı bir alışkanlık haline getirdiğine işaret edip, Beyrut'tan aldığı La Syrie (Territoire, Origines Ethniques et Politiques) adlı kitaptan bahsettiği bir mektubunda, "Bu kitabı gözlerim, kütüphane camekânlarında, bulunduğum memleketin ahvâl-i umûmiyyesi hakkında bir rehber ararken Fransızca kitâblar satan bir kitâbcı dolabında buldum." diyerek (1914, s. 143), gittiği ülkelerden kitap topluyor olmasının sebeplerine dair bir açıklama yapan Hümâm'ın sözünü ettiği “tutkulu” alışkanlık bağlamında, bir başka yazarın, satın aldığı bir kitaba ödeme yaparken duyduğu hazzı tarif etmek için kullandığı şu ifadeler oldukça çarpıcıdır; "Kitapçının istediği parayı memnûniyetle vererek kitabı almakla rûhumun ne büyük bir atş-ı irfânını tatmîn etmiş olduydum!” (Hafız İbrahim, 1913, s. 247)

Hâris bin Hümâm ve Hafız İbrahim gibi isimlerin bazı kitapları temin etme süreçlerine dair hatıralarını naklederken kullandıkları dilin aynı zamanda lirik bir şekilde ifade edilmiş bir "hazzı" çağrıştırıyor olması, İslam toplumlarında kitap ve kütüphanelere duyulan ilginin estetik boyutlar taşıyor olmasının da bir sonucudur. Bu eğilimin egemen olduğu çağlar boyunca, geleneksel kitap üretim tekniklerine sahip olan çeşitli coğrafyalarda kitap üretimi yapan müstensih ve hattatlar, bu üretimin her aşamasında kutsal bir görevi yerine getirmekte oldukları 
düşüncesi ve bir sanat eseri yapıyor olmanın heyecanıyla çalışmıştır. Kitaplara dolayısıyla da kitapların içeriklerine duyulan saygının mümkün olduğu kadar asil süslemelerle ifade edilmesi gerektiği şeklinde bir zihniyetin yansıması olan İslam dünyasındaki kitap geleneğinde, doğal olarak kitap üretimi de ayrı bir "sanat" olarak düşünülmüştür (Pedersen, 2013, s. 53-124). Dolayısıyla kitapların sadece entelektüel bir veri kaynağı değil, aynı zamanda estetik birer nesne olarak yorumlandığı çağlar boyunca kitap ve kütüphane kültürüne katkı sağlamış olan bazı kitap muhibbân ve mecânînleri, aynı zamanda birer sanatsever olarak da kültür tarihine mütevazı katkılar sağlamıştır.

Bu zeminde sanatsal boyutlara sahip olduğu da anlaşılan kitap muhibliğinin, muhatabının ruh dünyasındaki yansımalarını anlayabilmek adına çarpıcı, ama bir genelleme için elbette “münferit” duran entelektüel ve sanatsal ilgilerin Tevfik Bey’in kitaplarla kurduğu ilişki için de söz konusu olduğu tahmin edilebilir. Bu bağlamda 1912 yılının Temmuz ayında aynı zamanda uzak coğrafyalardaki kitap ve kütüphaneleri keşfetmek üzere de yola çıkmış olan Tevfik Bey, yol güzergâhındaki Mersin'de konakladığı sırada, şehirdeki Amerikan misyonerlerine ait bir bina kompleksindeki gözlemlerini anlatmaya, içerisinde çeşitli dillerden kitapların bulunduğu kütüphane salonundan başlamış, bu sırada tanıştığı Ermeni bir kitapçıyla görüşmesini anlatmıştır (S. M. Tevfik, 8 Ağustos 1912, s. 446). Kitapçıda geçen benzer bir deneyimi aktardığı İskenderun'dan sonra bazı mektuplarında, yolculuğu boyunca çeşitli yerlerden kitap temin ettiğine işaret edecek şekilde, satın aldığı kitapları da anlatan Tevfik Bey, Bağdat'ta satın aldığ 1 bir kitaptan bahsederek, aynı zamanda İran'ın Güristan eyaletine bağlı Peştguh'un - Ebu Azzâre adlı - valisi tarafından yazılan bir kitap temin ettiğini nakletmiştir (S. M. Tevfik, 5 Haziran 1913, s. 218). Bölgedeki hayvanlar ve avcılığa dair olan kitabın, aynı zamanda yazarının zekâsının da bir örneği olduğunu söyleyen Tevfik Bey, mektubunda yer alan bu detayla, yolculuğu sırasında temin ettiği kitapları ertelemeden okumak konusunda da hassasiyet gösterdiğini düşündürmektedir.

Hindistan'a vardığında, yanında, dönemin ulaşım ve nakliye koşullarında özel ilgi duymayan birinin taşıyacağı eşyalar arasında yer alması çok da mümkün olmayan kitaplar bulunduğuyla ilgili bir anekdotu aktaran Tevfik Bey, "Küçük Londra" dediği Bombay'a vardığında, bir eşya muayenesine tabi tutulmuştur. Eşyalarının tetkiki sırasında çantalarında bulunan kitapları fark eden gümrük görevlisi, kitapları kontrol ederken Tevfik Bey’in uyruğunu öğrenmek istemiş, "Osmanlı tebe'ası” olduğunu öğrendikten sonra, yanında taşıdığı kitaplarıyla birlikte oteline gitmesine izin vermiştir (S. M. Tevfik, 24 Temmuz 1913, s. 328).

Seyahat yazılarında kitaplarla kurduğu ilişkinin alelade bir ilginin çok ötesinde hem entelektüel bir merak hem sanatsal bir ilginin beslediği teknik ve estetik bir uzmanlıktan kaynaklandığını belli eden detaylar da vermiş olan Tevfik Bey, bunları bazen birkaç cümleyle bile olsa okuyucularıyla paylaşmıştır. Bu bağlamda gezip gördüğü yerlerde yaptığı sahaf ziyaretlerini ciddi bir kitap meraklısı olarak gerçekleştirdiğini işaret edecek şekilde, ayrıntılı bir deneyimini aktaran Tevfik Bey, birkaç hafta kaldı̆̆ı Seylan Adası'ndaki gözlemlerini aktarırken, Kandy adlı kentte üç-dört "kitâbhâne" bulunduğunu ama bunların en iyisinin Oryantal Kitâbhânesi (Oriental Library) olduğunu nakletmiştir. Burada bulunan İbranice, Keldanice, Arapça, Farsça, Urduca ve Sinha dilindeki çok sayıda el yazması kitabı tarif ederken, teknik özelliklerinden de bahsetmiş, bir kısmının "sanatkârane" ciltlerine dokunduğunu ifade etmiştir. Kapaklarında yerel dinlere ait motif ve semboller bulunan bazı 
kitapların sayfa yapılarını, "Kâğıdları bizim dülgerlerin kalın ve yumuşak talaşlarına benzer bir nevi' yaprak kabuğu" ifadeleriyle tarif ederken; "yazıyı muhâfaza etmek hâsiyetine mâlik olan" bu kabukların üzerindeki ibârelerin, "âdetâ kurşun kalemle yazılmışa" benzediğini anlatmıştır (S. M. Tevfik, 18 Aralık 1913, s. 234). Gerek Oryantal Kitâbhânesindeki kitaplar gerekse farklı yerlerde rastladığı bazı kitapları tarif ederken kullandığı "gāyet nefîs ve dayanıklı kitap kapları" gibi satırlarıyla (S. M. Tevfik, 25 Haziran 1914, s. 289), kitapların teknik ve estetik detaylarına gayet hâkim olduğunu ortaya koymuştur.

Özellikle Hindistan söz konusu olduğunda, gittiği kentlerin tarihi geçmişine de vâkıf olduğu anlaşılan Tevfik Bey, tarihi derinliğiyle ele aldığı kentleri anlatırken, geçmişte oralarda bulunan kütüphaneler ve bünyelerindeki kitaplara değinen detaylar vermeyi de ihmal etmemiştir (S. M. Tevfik, 28 Mayıs 1914, s. 224; S. M. Tevfik, 26 Mart 1914, s. 52; S. M. Tevfik, 2 Nisan 1914, s.72). Tevfik Bey'in Güney Asya seyahatinin aynı zamanda yeni kitaplar ve kütüphaneler bulmak üzere bir keşif yolculuğu olarak okunmasını sağlayacak pek çok başka detay bulunan mektupları, Sebîlürreşâd dergisinde, Hindistan Mektupları başlığıyla yer bulmuştur. Gidilen bölge, ülke ve kentin konumuna göre deniz ve kara yolculuklarıyla gerçekleştirdiği ziyaretler ve buralardaki gözlemlerini İslam dünyasının içinde bulunduğu sosyokültürel ve ekonomik duruma dair tespitleriyle harmanlayarak anlatan Tevfik Bey, nihayet 1914 ortalarında yolculuğunu tamamlarken, akıllarını başlarına alması gereken Müslümanların "uyudukları uykudan" ne zaman uyanacaklarını sorarak, bir zamanların şanlı imparatorluklarına ev sahipliği yapmış olan Hindistan'da, Delhi'de bulunan yıkık duvarlar içerisinde "gayri ihtiyarı" gözyaşı döktügünü anlatmıştır (S. M. Tevfik, 25 Haziran 1914, s. 291). Bu çalışmada, yaşamının Osmanlı basın tarihine dâhil olmasını sağlayan Güney Asya seyahatiyle geçen yılları Muhibbân-1 Kütüp geleneği bağlamında ele alınan Tevfik Bey’in Hindistan'dan ayrıldığı sıralarda, dünya düşünce tarihi için önemli bir olay da yaşanmış, kitap kültürünün önemli eserleri arasında yer alan ve İmâm-1 Gazzâlî tarafından yazılan orijinal bir kitabın bulunduğuna dair haberler çeşitli gazetelere yansımıştır ("İmâm-1 Gazzâlî’nin Mühim Bir Kitabı Bulunmuştur”, 1914, s. 243). Böyle bir haberin, söz konusu keşif sırasında Hindistan'da bulunan bir "kitap muhibbi” açısından ne kadar heyecan verici olduğu düşünüldüğünde, Tevfik Bey’in kitaplara uzanan keşif yolculuğu açısından da önemli olduğunu söylemek pekâlâ mümkündür.

Mektuplarından birinde bir "kitap medeniyeti" olan İslam dünyasında kitaplarla teşrik-i mesaisi en fazla olan temsilcilerin başında gelen ulema ve sair kişilerin "iki satırlık Arapça bir kitabı dâhi okuyamaz" oluşundan şikayet ederek, "sırf kağıt yığınlarıyla" uğraşmanın nafile olduğuna işaret eden Tevfik Bey'in, Güney Asya seyahati sırasında gittiği her yerde topluma ve dolayısıyla yerel yaygın dillere nüfuz edebilmesini sağlayan şey, onun da tıpkı - aralarında yukarıda bahsedildiği üzere Ali Emîrî Efendi'nin de bulunduğu -dönemin başka “bibliyofilleri” gibi, çok fazla dil biliyor olmasıyla da ilgilidir. Nitekim bu çok yönlü gazeteciyi İstanbul'da yaşayan İranlılardan biri olması hasebiyle hatıralarına dâhil ederek, onun için "güzelliği ile Zengî, çalışkanlığı ile Türk, huyu ile Rum ve sözü ile Hint” tarifini kullanmış olan Sasanî’ye göre, Tevfik Bey, Farsça, Türkçe, Arapça, Hintçe ve İngilizce konuşabilmektedir (2006, s. 3132). 


\section{Küllerinden Doğan Bir Kütüphane ve "Fihrist-i Kütüphane-i Hususi" 3}

Güney Asya seyahatini 1914 yılının Haziran ayında tamamlayarak İstanbul'a dönen (S. M. Tevfik (18 Haziran 1914, s. 273), sonraki yıllarda Sebîlürreşâd'da yayımlanan Türkçe makaleleriyle eş zamanlı olarak, Farsça makaleler yazdığı Haver'de ayrıca idareci olarak da yer alıp, gazetecilik faaliyetlerine devam etmiştir. Bu dönem, aynı zamanda Tevfik Bey’in kitaplarla ilişkisini İran tarihi açısından oldukça önemli bir yere yerleştirerek, sahip olduğu kütüphanesini iki ayrı döneme ayıran Bashari'nin bahsettiği “ikinci” kütüphanesinin nitelik kazanmaya başladığı dönem de olmalıdır. Nihayet yukarıda bahsedilen çoklu dil hâkimiyeti sayesinde, Güney Asya seyahatinde - muhtemelen öncesinde de - zaten var olan dostluk ve ilişkilerini pekiştirdiği gibi kitap ve kitapçılar bağlamında yeni bağlantılar kurmuş olduğu da tahmin edilebilecek olan Tevfik Bey, bu ikinci dönemde, coğrafi sınır ve dil engeli yaşamadığı kitaplar toplamaya devam etmiş gibi görünmektedir. Üstelik Tevfik Bey, bu dönemdeki yazılarında, Güney Asya seyahatini tamamladıktan sonra kitaplara olan ilgisini, orijinaline ulaşılamadığı bazılarının teminini, farklı yöntemlerle sağlayacak şekilde geliştirdiğini de düşündüren detaylar vermektedir. Bu bağlamda Keşf-i Telbis (ya Do Ruyi ve Nireng)-i Íngilis adlı bir kitabı, fotoğraflarının çekilmesi yoluyla temin ettiğini anlatmış olması (S. M. Tevfik, 5 Eylül 1918, s. 69), fotokopi teknolojisinin insan hayatına dâhil olmasında sonra kitap temini için alternatif bir çözüm yoluna dönüşmesindeki gibi, orijinal nüshalarına ulaşamadığı bazı kitaplara "fotoğraflarını" çekerek ya da çektirerek bile olsa temas ettiğini göstermektedir. Dolayısıyla Tevfik Bey, gazetecilik mesleğini çok dilli mecralarda, çok uluslu hedef kitlelere, çok dilli olacak şekilde sürdüren bir gazeteci olarak da kitap koleksiyoneri olarak da dönemin standartlarının çok üzerinde bir profil çizmektedir.

Nihayet bu zeminde, Bashari'nin bahsettiği -ikinci- kütüphanesini kuracak olan Tevfik Bey, temelinde 1909 yılında gerçekleşen büyük yangında küle dönen kütüphanesinden miras kalan kitapların olduğu bu kütüphaneyi, belki de benzer bir yıkımdan -en azından künyeleriylekurtarabilmek için ayrıca bir "fihrist" hazırlayıp müstakil bir kitap olarak yayınlamıştır (S. M. Tevfik, 1927). Kapağında "Fihrist-i Kütüphane-i Hususi" ibaresi bulunan ve 1927 yılında İstanbul Marifet Matbaasında basılmış olan fihriste hem Osmanlı kaligrafisiyle Türkçe hem Farsça önsöz yazan Tevfik Bey, önsözünde değindiği meseleleri, fihristin sonunda ayrıca İngilizce olarak da tekrar etmiştir. Kullandığı üslup ve sembol değerlerden hareketle, Tevfik Bey'in, kütüphane fihristinin ilk ve son sayfalarına farklı dillerde yerleştirdiği önsözlerini özgün bir "kebîkec" olarak da değerlendirmek mümkündür. El yazması kitapların üzerlerine, güvelerden korunması için yazılan ve tılsımlı olduğuna inanılan "yâ kebîkec", "yâ hafîz yâ kebîkec" gibi ibarelerden oluşan bu kelimelerin nihayetinde kitabı "zırhlamak" ve "zararlılardan korumak" üzere yazıldığı düşünüldüğünde, Tevfik Bey de nadide kitaplardan oluşan kütüphanesini kitabın ruhundan anlamayan "zararlılardan" korumak için fihristin ön ve arka sayfalarında "Bu kitapları satan medet kazanmayacağı gibi manen pek büyük şeyler kaybedecektir." uyarısında bulunmuş, nihayet "Huz ma' safâ da'ma-keder" (Saf temizi al kederden uzak dur!) demiştir.

\footnotetext{
${ }^{3}$ Seyyid Muhammed Tevfik Hemedanî’nin biyografisiyle ilgili araştırmalarım sırasında, 1927 yılında yayınlamış olduğu hususi kütüphane fihristini fark etmemi sağlayan çağdaş muhibbân-1 kütüp Prof. Dr. Ali Birinci'ye ve bu makalenin yazım aşamasındaki katkılarından dolayı Dr. Harun Tuncer'e teşekkürlerimle.
} 
Bir kitap muhibbinin estetik ve sanatsal derinliği olan zihin dünyasında özgün bir "kebîkec" uyarlaması olarak düşünülebilecek olan çok dilli önsözlerini oldukça samimi bir üslupla kaleme almış olan Tevfik Bey, kütüphanesindeki kitapların tamamının çağdaş bir tarzda ve birçoğunun Avrupa'da ciltlenmiş olduğunu anlatmaktadır. Yine aynı önsözündeki ilk cümlelerinden itibaren oldukça hassasiyet duyduğunu belli ettiği kitaplarının, tamamının temiz ve yeni durumda olduğunu belirtmiştir. Kitapların teminini 20-30 y1llık bir periyoda dayandırıyor olması, kütüphanesinin hem 1909'daki büyük yangından kurtardığı hem de sonradan temin ettiği kitaplardan müteşekkil olduğunu göstermektedir. Her bir kitabı bizzat basıldıkları ülke ve şehirlerden getirmek için her türlü maddi ve manevi fedakârlığı gösterdiğini anlatan Tevfik Bey, kitaplarının birçoğunun, değil İstanbul, İran, Suriye, Mısır, Hindistan ve hatta Avrupa'da dâhi başka nüshaları bulunmayan nadide eserler olduğunu söylemiştir.

S. M. Tevfik'in zengin ve nadide eserlerden oluşan kütüphanesini takdim ederken kullandığ 1 , -elbette verilen emekten de kaynaklanan- beğeni ifadeleri bir yana, kütüphanesi için müstakil bir fihrist hazırlamış, üstelik bu fihristi detaylarına rahatlıkla nüfuz edilebilecek, kolay anlaşılır bir içerik dizaynıyla yapmış olması bile dönemin koşullarında oldukça önemlidir. Zira, Tevfik Bey'in hususi kütüphanesine ait bir fihrist yayınladığı yıllarda, değil hususi bir kütüphanede bulunan kitaplar, resmi kütüphanelerde bulunan kitaplar bile çok zaman sadece sorumlularının vâkıf olduğu kaotik bir dağınıklık içerisinde bulunmaktadır. Benzer şekilde kitap kataloglaması, konu ve yazar tasnifi yahut bünyesinde toplu kitaplar bulunan herhangi bir kitap mekânında bulunan kitapların künyelerini sistematik bir şekilde verebilecek listelere rastlamak dâhi zordur. Oldukça sistematik ve anlaşılır bir içerik dizaynına sahip olan Fihrist-i Kütüphane-i Hususi'nin yayınlandığı yıllarda, bir şekilde hazırlanmış nadir fihristlerin kaotik durumuna işaret eden bir örnek, yine bu çalışmada temel veri kaynağı olarak kullanılan Sebîlürreşâd dergisine yansımıştır. Bu bağlamda o dönemde İstanbul halkının yüzde doksanının, şehirdeki tek genel kütüphane olmasına rağmen, kırk yıldır hizmet veren Kütüphane-i Umumi-i Osmaniden (Beyazıt Devlet Kütüphanesi) bile bihaber olduğunu söyleyen Ferid Bey, buradaki fihristlerin durumunda da bahsederek, şöyle devam etmiştir; "Evvelâ fihrist nâmıyla kitapların ismi yazılı ufak bir mektep defterinin muhtelif nüshaları mevcûd olmadığından bir kitap intihâbı için sâ'atlerce nevbet beklemek mecbûriyetinde kalınıyor. Meselâ bir tarih kitabı bulmak için bu karma karışık yazılı defteri tamamıyla gözden geçirmek lâzım geliyor.” (1919, s. 16). Ferid Bey’in devamında söz konusu kütüphanedeki çok tanıdık- özensizlik, dağınıklık, takipsizlik ve nihayet nitelikli bir okuyucu için kaotik olan sorunlardan bahsettiği satırları, fihristlerin durumuna dair tespitleriyle düşünüldüğünde, Tevfik Bey’in kendi kütüphanesine ait fihristin, aslında gayet profesyonelce hazırlanmış, dönemin koşullarında oldukça ileri görüşlü, özgün bir dizayna sahip ve nihayet II. Meşrutiyet Dönemi kitap, kütüphane kültürü açısından da değerli bir örnek olduğunu göstermektedir.

Kitap ve kütüphane kültürüne dair dönemsel değeri böylece ortaya konulmuş olan Fihristi Kütüphane-i Hususi'ye göre, basma kitaplar bakımından da nispeten zengin olan kütüphanenin "muhibbi”" Tevfik Bey, kütüphanesini adeta biyografisinin de yansıması olacak şekilde oluşturmuştur. Zira kütüphanesinde bulunan ve tıpkı kendi kökenindeki çeşitlilik gibi basım yerleri de oldukça farklılık gösteren bu kitaplar, yine Tevfik Bey’in çoklu dil yeteneğiyle uyumlu olacak şekilde çeşitli dillerde yazılmıştır. Osmanlı basın tarihine gazetecilik yönüyle dâhil olmuşsa da ayrıca -farklı aidiyetlerinin her biri için- oldukça nitelikli bir eğitimci, seyyah, 
çevirmen, mütercim ve nihayet uzman bir kitap koleksiyoneri olan Tevfik Bey'in tüm bu profesyonel uğraşıları gibi çeşitli konuları ele alan kitaplardan oluşan zengin bir içeriğe sahip kütüphanesinde bulunan kitaplarının listelendiği fihristte adı geçen eserler, isim, cilt adedi, dil, konu, yazar/derleyen, baskı tarihi ve nihayet basıldığı matbaaya dair bilgiler verecek şekilde detaylandırılmıştır. Tevfik Bey'in şahsi kütüphanesindeki kitapları listelediği bu fihristin bir başka özgün yanı, adı geçen kitapların basıldıkları şehirlere göre sıralanmış olmasıdır. $\mathrm{Bu}$ bağlamda fihristin ilk sayfalarında İstanbul'da basılan kitaplara yer verilmiş (1927, s. 1-8) ardindan sirasiyla, Avrupa (1927, s. 9), Paris (1927, s. 10-11), Petersburg \& Rusya (1927, s. 12), Londra (1927, s. 12-15), Amerika (1927, s. 15), Leipzig (1927, s. 16), Leiden (1927, s. $17-$ 18), Avrupa (1927, s. 19), İran (1927, s. 20-21), Beyrut \& Suriye (1927, s. 22-24) El-Bilad-ül Rabbiyet (1927, s. 24), Misir (1927, s. 25-33), Hindistan - Bombay (1927, s. 33-34), Hindistan (1927, s. 35), Hindistan - Kanpor (1925, s. 35), Hindistan (1927, s. 36), Hindistan - Lahor (1927, s. 37), Hindistan - Kalküta (1927, s. 38), Hindistan (1927, s. 39) baskılı kitaplar listelenmiştir.

Paris, Londra, Leipzig, Leiden gibi çeşitli Avrupa ülkeleri ve Petersburg'da basılmış toplamda 209 kitabın bulunduğu kütüphanedeki 2 adet kitabın Amerika menşeili olması Tevfik Bey’in coğrafi sınır tanımayan kitap muhibliğinin, nihayet okyanus ötesine kadar uzandığını göstermektedir. Kütüphanesini oluştururken kitapların tamamını bizzat basıldıkları yerden getir(t)miş olan Tevfik Bey'in bazılarını okyanusları aşarak temin ettiği kütüphanesinde, basım yeri İstanbul olan 226 adet kitap bulunmaktadır. Baba tarafindan memleketi olan İran'da basılmış 49 kitabın bulunduğu kütüphanesinde, basım yeri Beyrut, Suriye ve çeşitli Arap ülkeleri olan 65 kitap ve Misır menşeili 187 adet nadide eser bulunmaktadır. Muhtemelen en azından bir kısmını Sebîlürreşâd muhabiri olarak Güney Asya seyahatine çıktığı sırada temin ettiği Güney Asya menşeili kitapların sayısı toplamda 172 adettir. Bombay, Behupal, Haydarabad, Lahor, Kampor, Marteser, Kalküta ve Luknov gibi şehirlerde basıldıkları anlaşılan bu kitapların arasında bulunan ve Asiatic Society of Bengal (Bengal Cemiyet-i Asyaiyesi) tarafından yayınlamış olan bazı nadir eserler vardır ki -kendi ifadesiyle- Türkçülük ve Türkiyat meseleleri bağlamında hem içerik hem de nitelik açısından oldukça kıymetlidir. Yaklaşık 150 yıllık olan bu eserlerde, Hindistan'daki Türk-Moğol padişahlarının sultanları ile ilişkileri, toplumun örf ve adetleri, dini ve resmi merasimler, Hindistan'daki emir, vezir ve ayanların faaliyetleri anlatılmaktadır. Aynı zamanda Hindistan'daki Türk medeniyetine dâhil olan devletlerin bilimsel ve kültürel faaliyetlerine de yer verilen bu eserlerde Güney Asya'daki Türkİslam medeniyetinin "ihtişamlı” dönemlerine ait kapsayıcı bilgilere ulaşmak mümkündür. Eserlerin dönemin ünlü yazarlarınca derlenerek yazıldığını ifade eden Tevfik Bey’in işaret ettiği üzere, söz konusu eserler Kalküta'da kurulan ve en az akademi kadar önemli olan Bengal Cemiyet-i Asyaiyesi tarafindan neşredilmiştir (1927).

Fihristin devamında sıralanan Arapça, Farsça ve Türkçe dillerindeki 27 adet el yazması kitap (1927, s. 39-40) da dâhil olmak üzere, S. M. Tevfik Hususi Kütüphanesinde toplam 917 nadir eser bulunmaktadır. Kütüphanedeki yazma eserler arasında adı geçen 695 (1296) tarihli Tezkire-i Evliya ve 874 (1469) tarihli İlahinâme hem oldukça nadir oluşları hem de müellifleri olan Ferideddin-i Attar'ın önemli eserlerinden olmaları hasebiyle oldukça dikkat çekicidir (1927, s. 40). Nihayet din, tarih, coğrafya, felsefe ve siyaset konularıyla ilgili çok sayıda kitap sahibi olan Tevfik Bey'in kütüphanesinde yerli yabancı masal, şiir, tiyatro ve hatta sinema 
kitapları göze çarpmakta, "Hicâb etsin tabîat yerde kalmış kâbiliyetten” diyen Namık Kemal ve daha birçok önemli isme ait kitap listesi sayfalarca sürmektedir. Bizzat yönettiği Haver gazetesi de dâhil, çeşitli gazete ciltlerinin yanı sıra bazı kütüphane fihristlerinin de bulunduğu kütüphanesiyle ilgili profesyonelce hazırlanmış -fihristin bir nüshası üzerinde bulunan el yazısının kendisine ait olması durumunda- Fihrist-i Kütüphane-i Hususi, Tevfik Bey'in hayatının son yıllarında nerede yaşadığıyla ilgili de fikir vermekte, fihristin bir nüshasına el yazısıyla kaydedilen "Arnaout-Keuy, Bosphor” ifadesi (Kut, 1994, s. 19) o y1llarda Arnavutköy’de yaşadığını düşündürmektedir.

\section{Sonuç: "Hicâb etsin tabîat yerde kalmış kâbiliyetten"}

Fihrist-i Kütüphane-i Hususi'nin yayımlandığı yıl, aynı zamanda Seyyid Muhammed Tevfik Hemedanı̂’nin Türk matbuatındaki görünümlerinin de kaybolduğu bir dönemin parçasıdır. Bu döneme ait resmî yazışmalara yansıyan ilginç bir gelişme, Tevfik Bey'in Millî Mücadele dönemi ve Cumhuriyet'in kuruluşundan sonraki ilk yıllarda da bizzat gerçekleştirdiği uzak mesafe yolculuklarıyla, özellikle İstanbul'dan Güney Asya'ya uzanan güzergâhtaki kitap dünyasıyla doğrudan temas kurma imkânına sahip olabileceğini düşündürmektedir. Bu bağlamda değerlendirilebilecek bir yazışma, 1924 yılına ait bazı resmî belgelere yansımış, Tevfik Bey'in özel bir izinle Hilal-i Ahmer Heyetinin tercümanı olarak Hindistan'a gönderilmesi gündeme gelmiştir (BOA, HR, İM, 97/24; BOA, HR, İM, 238/128). Bu noktada Hilal-i Ahmer Heyeti'nin tercümanı olarak Hindistan'a gönderilmesi teklif edilen Tevfik Bey adlı kişinin, bu biyografik çalışmanın konusu olan S. M. Tevfik Bey olduğuna işaret eden net bir künye detayına ulaşılamadığını belirtmek gerekir. Ancak bahse konu girişim bağlamında bölgeye tercüman olarak gönderilecek birini arayan herhangi bir organizasyonun -normal koşullarda- İngilizce ve Hintçe bilen ve bölgeyi iyi tanıyan birine ihtiyaç duyacağı aşikârdır. $\mathrm{Bu}$ durumda, dönemin koşullarında ortalamanın çok üstünde olan bu meziyetlere sahip ve adı Muhammed Tevfik olan birden fazla tercümanın var olması da bir ihtimalse de böylesi sınır aşırı önemli bir girişimde, evvelden birebir aynı güzergâhta tecrübesi ve Hilal-i Ahmer'le teması olduğu için S. M. Tevfik'in tercih edilmiş olması daha büyük bir olasılık gibi görünmektedir. Bu zeminde, tercümanının kimlik künyesi gibi gerçekleşip gerçekleşmediği de şimdilik net olmayan bu sınır aşırı girişimde adı geçen kişinin de kendisi olması durumunda, Tevfik Bey, Türkiye Cumhuriyeti'nin kuruluşundan sonra bile hâlâ çok yönlü kimliği ve uzmanlıkları sayesinde aranan bir profil çiziyor gibi de görünmektedir. Nihayet bu olası gelişme, uzun yıllar önce yaptığı Güney Asya seyahatine benzer yolculukları tekrar tekrar "yapmış gibi" duran Tevfik Bey'in, Osmanlı tarihi bağlamında II. Meşrutiyet Dönemi ve nihayet Cumhuriyet tarihindeki görünümleriyle derinlemesine araştırılması durumunda hem matbuat tarihi hem de kitap ve kütüphane kültürüne dair bambaşka "sürprizler" vaat eden bir yaşam sürdürdüğünü düşündürmektedir.

Yapılan araştırmalarda, hayattayken onunla temas edip sahip olduğu çok yönlü birikimden bahseden -şimdilik - tek isim olan Sasanî'nin ifadelerini tekrarla, "güzelliği ile Zengî, çalışkanlığı ile Türk, huyu ile Rum ve sözü ile Hint” olan, Farsça, Türkçe, Arapça, Hintçe ve İngilizce konuşabilen Tevfik Bey'in Cumhuriyet'in ilanından sonraki yaşamına dair araştırmalar devam etmektedir. Tevfik Bey, yaşamıyla, mensubu olunan toplumsal, kültürel, inançsal, sosyoekonomik, siyasi ve nihayet coğrafi evrenin geçmişi üzerine düşünürken, içinde 
bulunulan yahut maruz kalınan gerçeklikten rahatsızlık duymuş, kalem ve kelamıyla meramını anlatmaya çalışmış aksiyoner bir profil çizmektedir. Yaşamları boyunca, çağdaşları olan modernist İslamcıların idealize ettiği geleceğin örnek profillerinden biri olmaya çalışmış bir entelektüel portresi çizen Tevfik Bey ve benzeri rol modellerin yitik yaşam hikâyeleriyle birlikte zihniyetlerini gün yüzüne çıkarmak, "yere düşmüş kabiliyetten” hicap duyması gereken tarihin esas meselelerinden biri olmalıdır.

Yaşamları boyunca sadece kalem ve kelamla yetinmeyen, inisiyatif alarak sahaya açılıp günümüz ulaşım imkânlarında dâhi oldukça zorlu ve uzun yolculuklarla ulaşılabilen coğrafi ve sosyokültürel mesafeleri aşan nadir bireylerden oluşan bir kuşağın zihin dünyasının anlaşılması, siyasetin, tarihin temel belirleyeni olmaktan çıkmasını ve nihayet devirlerin insan faktörü ve zihniyet biçimleriyle anlaşılmasına sağlayacaktır. Şimdiki zamanı, araçsal siyasetle tümüyle kuşatılmış, tarih algısı "zamanı anlamak" için değil bir "temenniyi tamamlamak" için evrimleşmiş olan bireylerden oluşan bir toplumun, geçmişi de şimdiki zamanı da geleceği de siyasetin değil bireylerin inşa ettiğini anlaması, tüm bu zaman dilimlerine egemen olan zihniyetler ve bunları temsil eden rol modellerin tekrar tarihin konusu haline gelmesiyle mümkündür. Hükümdarları saraylarda, komutanları savaş meydanlarında, düşünceleri kitaplarda, kitapları kütüphanelerde payidar eden de ziyan eden de siyaset değil bireyler ve bireylerin zihniyet yapısıdır. Tarih yazımında özellikle Marc Bloch'un dikkat çektiği üzere, kurguya zihniyet ve zihniyetlerin de dâhil edilmesi, örneğin II. Meşrutiyet Dönemi özelinde bu döneme ait gerçek portreyi sosyal bilimlerin ifade yöntemleriyle tarif etmek pek mümkün değilse bile en azından portredeki tasvirlerin gerçek boyutları ve kontrast farklılıklarını ortaya koyacaktır.

Geçmişi, üzerinde çeşitli tasvirler bulunan bir tablo ve geleceği de bu tablonun fiziki ve estetik imkânlarıyla her yeni gün yeniden tasarlanan bir resim olarak düşünecek olursak, yarınını inşa edemediği için geçmişe saplanan toplumların temel meselesi, geçmiş zaman tablolarının parçalarıyla ilgili görünse de aslında (tabloyu oluşturan renkler, şekiller ve diğer detaylar muğlak bırakıldığı için detaylarını göremedikleri) bütünün yorumu üzerinde çatışıyor olmalarıdır. Dolayısıyla parçalarla ilgili gibi duran ama parçaların gerçek boyutları hep ihmal edildiği ya da ikinci planda kaldığı için zaman içerisinde bütünün toptan reddine yahut kutsanmasına dönüşen bir geçmiş zaman algısının, yerini parçaların gerçek boyutlarının hesaba katıldığı bir aklı selime teslim etmesi, zihniyet tarihçiliği ve bu tarihçiliğin ürünü olan çalışmalarla mümkündür. Tarihsel olguların bireylerin psikolojik süreçleriyle birlikte ele alındığı bu yaklaşım, Bloch'un ifadesiyle, yazgısı içinde bulunulan fiziksel dünyanın ağırlığıyla şekillenen bireyin gündelik yaşamına dair tasvirleri, tarihin asıl ve doğal konusu haline getirmektedir, ki bu da nasıl ortaya çıktığı bilinmeyen ama bir şekilde devam eden ya da var olan sembolik eylem ve toplumsal hallerin ardındaki zihniyetin ortaya çıkmasını sağlar.

Bu zeminde kitap ve kütüphane kültürünün II. Meşrutiyet yıllarındaki serüveniyle ilgili farklı bir profilin yaşam hikâyesini kitap muhibliği bağlamında ele alan bu çalışma, portresini çizmeye çalıştı̆̆ çoklu ilgi ve yeteneklere sahip Tevfik Bey'in gündelik yaşamına dair kesitleri bir araya getirmiştir. Hayatının neredeyse yirmi yıllık bölümüne ait ipuçlarını, dönemin çeşitli gazete ve dergilerine yansımış farklı dillerdeki yazılarında bulmanın mümkün olduğu bu profil, nihayetinde bir zihniyeti temsil etmekte, bir devrin toplum için inisiyatif alarak entelektüel üretim yapan zihniyetiyle ilgili fikir vermektedir. 
Osmanlı basın tarihindeki rolü, "S. M. Tevfik" imzası ve "Hindistan Mektupları" başlığıyla yazdığı seyahat yazılarından ibaret bilinen ama tam adı olan, Seyyid Muhammed Tevfik Hemedanî olarak sahip olduğu özgün kimliğiyle, 20. yüzyıl Osmanlı ve İran matbuat tarihi açısından oldukça önemli bir isim olan Tevfik Bey, aynı zamanda tek uğraş ve uzmanlık alanına sığmayan bir kuşağın temsilcisidir. Bu yönüyle, şimdiye kadar basın tarihindeki baskın görünümü gazetecilik kimliğiyle gerçekleştirdiği faaliyetlerden ibaretse de nihayet yeni araştırmalarla farklı uzmanlık ve meziyetlere sahip olduğu anlaşılan Tevfik Bey, siyasetçi, idareci, öğretmen, yazar, editör, seyyah, tercüman, mütercim, koleksiyoner ve nihayet bir kitap muhibbi olarak tüm kimlikleriyle aktif olduğu aksiyoner bir yaşam sürdürmüştür. Gerek ailevi kökenleri gerekse yine ailesinin İstanbul'dan Güney Asya'ya uzanan güzergâhtaki akrabalık ve ticari ilişkileri sayesinde, tüm bu coğrafi hat üzerindeki kültürlerle etkileşim içerisinde geçen yaşamını, çoklu dil yeteneğine dönüştürmeyi başarmış olması, Tevfik Bey’in yaşamının, hakkında farklı dillerde farklı görünümlerine dair kayıtlar bulunabilen nevi şahsına münhasır bir rol model olarak, aradan geçen bir asrı aşkın süreden sonra bile kapsamlı bir şekilde mercek altına alınmasını elzem kılmaktadır.

Bu çalışmayla Seyyid Muhammed Tevfik Hemedanî'nin birbirini besleyen ve her biri kendi başına yaşadığı dönemin ortalamasının üzerinde olan kimliklerine kısaca değinilmiş, kitap ve kütüphane kültürüne katkısı bağlamında bir kitap muhibbi olması ve sahip olduğu kütüphane merkeze alınmıştır. Mensubu olduğu kuşağın kitap ve kütüphane muhibliğine dair metinlerde öne çıkan ve makalenin girişinde bahsi edilen Ali Emîrî Efendinin sahip olduğu kütüphanenin niceliğine - belki de birinci döneminde yaşanan yangın nedeniyle - hiç ulaşamamışsa da içerik çeşitliliği açısından en az onun kadar zengin bir kütüphaneye sahip olduğu anlaşılan Tevfik Bey'in kitap toplama faaliyetlerinin şekli de Ali Emîrî Efendi'nin yöntemlerini çağrıştırmaktadır. Zira, kütüphanesinde bulunan bir kitabın ikinci cildini sahibiyle yüz yüze pazarlık edebilmek için bizzat istemesine bağlanan Yanya'dan Yemen'e tayinine bakılacak olursa (Oktay, 2009, s. 41). Tevfik Bey de tıpkı Ali Emîrî Efendi gibi kitap toplamak için uzun mesafe yolculuklar yapmayı göze almış, bu makalenin merkezinde olan yolculuklarından birini yine benzer şekilde dâhil olduğu kurumsal yapının bünyesinde gerçekleştirmiştir.

Güney Asya seyahati sırasında kaleme aldığı mektuplarda bahsini ettiği kitap ve kütüphaneler kadar sahip olduğu kitapların da hem fiziksel hem sanatsal hem de içeriksel derinliğine hâkim olduğu anlaşılan Tevfik Bey'in bu makalenin önceki bölümlerine yansıyan gündelik hayat kesitlerinden anlaşılacağı üzere, sadece İstanbul şehri ve Osmanlı tebaasıyla sınırlı kalmayan geniş bir coğrafyaya yayılan çok uluslu bir kitap uzmanlığı söz konusudur. Asya ve Avrupa'dan gelen çeşitli aidiyetler ve sosyal statülerden insanların, kitap ve kütüphane konusunda uzmanlığına başvurduğu Tevfik Bey, bu etkileşimler sırasında ortalama bir kitap okuyucusunun hayal edemeyeceği nitelik ve içeriklere sahip kitaplara rastlamış, kitapçılar dolaşmış ve kütüphaneler görmüş olmalıdır. Bu yönüyle Tevfik Bey, sadece bir kitap muhibbi değil, dönemin temel bilgi aktarım nesnesi olan gazeteleri, dergileri ve kitapları aracılığıyla yaşadığı çağın kelimelerle resmedilen görüntülerini takip edebilen bir seyirci olarak da düşünülebilir. Nitekim ortalama bir okuyucu yahut kitapseverin ufkunun çok üzerinde görüntüler alabilmesini sağlayan çoklu dil yeteneğinin, temas ettiği gazete, kitap ve 
kütüphanelerin içeriğine nüfuz etmesine en azından gözden geçirmesine olanak sağladığ1 aşikârdır.

Uzak coğrafyalara seyahat ederek buralardaki kitaplara ve kütüphanelere temas etme imkânı bulduğu da düşünüldüğünde, Seyyid Muhammed Tevfik Hemedanî, II. Meşrutiyet Döneminde kurmaya başlayıp Türkiye Cumhuriyeti'ne taşıdığı zengin kütüphanesiyle aslında imparatorluklar çağının farklı coğrafyalardan derlediği kültür mirasını tek bir çatı altında bir araya getirmiştir. Nihayet kitapların maddi yahut sosyokültürel bir yıkım, kopuş yahut savruluş sırasında fiziki olarak yok olmaları ihtimaline karşı hazırlanmışçasına, dünya kitap ve kütüphane tarihi açısından bir araya gelişleriyle dâhi oldukça değerli olan kitaplarının İstanbul'da kurduğu kütüphanesindeki listesini Fihrist-i Kütüphane-i Hususi'de kayıt altına alarak tarihe not düşmüştür. "Bu kitapları satan medet kazanmayacağı gibi manen pek büyük şeyler kaybedecektir" dediği kitaplarının vefatından sonra nasıl bir ahvalle karşılaştığı şimdilik bilinmese de gazeteci Tevfik Bey'in bir Muhibbân-1 Kütüp olarak da sürdürdüğü yaşamı boyunca, kitaplar konusunda, -kendi ifadesiyle, "saf temizi almaya" gayret ettiği anlaşılmaktadır.

Seyyid Muhammed Tevfik Hemedanî tarafından, yaşandığı dönemin koşullarında oldukça “çileli” yolculuklar ve uzak coğrafyalardan İstanbul'a taşınan kitaplarla kurulmuş özel kütüphanenin bir parçası olsa da zaman içerisinde farklı şehirlerdeki kitapçılara, kütüphanelere ya da özel koleksiyonlara dağılmış kitapların hepsinin değilse bile bir kısmının fiziki varlıklarını koruduğu umulmaktadır. Bu makale, tıpkı hayatının son dönemleri gibi, oldukça önem verdiği aşikâr olan kütüphanesinin Erken Cumhuriyet Dönemine karşılık gelen yılları da belirsiz olan S. M. Tevfik'in, kütüphanesinde bulunan koleksiyonla ilgili araştırmalar bağlamında yazılmıştır. Makalenin, aslında geçmişte S. M. Tevfik koleksiyonundan bir şekilde kopmuş ya da koparılmışsa da aradan geçen bir asra rağmen bir yerlerde fiziki varlığını korumayı başarabilmiş ama menşei bilinmeyen bazı kitapların keşfedilmesine ve çok yönlü kimliğini S. M. T. [س. م. م. ت imzasıyla üç harfe sığdırmış bir muhibbânın kitap mirasının bulunmasına hizmet etmesi umulmaktadır. 


\section{Kaynakça}

Bashari, J. (2017). Tevfik: Ruznamenegâr ve Majmooedar-e İranî dar Istanbul. Tahran, İran: Entesharat-e Varagan.

BOA, HR, IMM, 97/24, 11 Şubat 1924.

BOA, HR, IM, 238/128, 14 Şubat 1924.

Browne, E. G. (1914). Press And poetry of modern Persia. İngiltere: Cambridge University Press.

Efe, Â. (2009). Sebîlürreşâd. TDV İslam Ansiklopedisi, 36, 251-253.

Kabacal1, A. (2000). Başlangıcından günümüze Türkiye'de matbaa basın ve yayın. İstanbul: Literatür Yayınevi.

Kut, T. A. (1994). Terekelerde çıkan kitapların matbu satış defterleri, Müteferrika Kitabiyat Dergisi, 2, 3-24.

Oktay, T. (2009). Bir kitap tutkunu Ali Emiri Efendi, Birlik Dergisi, 3, 40-42.

Pedersen, J. (2013). İslam Dünyasında kitabın tarihi. (2. bs.). M. M. Karagözoğlu (Çev.). İstanbul: Klasik Yayınları.

Ruskin, J. (2016). Susam ve zambaklar (Kitaplara ve kadınlara dair). T. Turgut (Çev.). Ankara: Doğu Batı Yayınları.

Sasanî, H. M. (2006). Payitahtın son yıllarında bir sefir. H. Uygur (Çev.). İstanbul: Klasik Yayınları.

Tayşi, M. S. (1989). Ali Emîrî Efendi. TDV İslam Ansiklopedisi, 2, 390-391.

Ülkütaşır, M. Ş. (1946). Büyük Türk dilcisi Kâşgarlı Mahmut. İstanbul: Türk Dil Kurumu.

Yazıksız, N. Â. (2020). Kitap. İstanbul: Büyüyenay Yayınları.

Ferid (Bey). (1919, 13 Şubat). Kütüphane ve kitaplarımız. Sebîlürreşâd,, 16(391), 16.

Hafız İbrahim. (1913, 25 Aralık). Büyük üstad Havı Zihni Efendi Merhum. Sebîlürreşâd, 11(276), 247.

Hâris bin Hümâm. (1914, 30 Nisan). Mekâtîb: Beyrut mektupları - 6 - maarif. Sebîlürreşâd,, 12(294), $140-142$.

Ispartalı Hakk1.(1919, 2 Ocak). Okuyorlar mı?. Sebîlürreşâd, 15(385), 376-377.

İmâm-1 Gazzâlî’nin Mühim Bir Kitâbı Bulunmuştur. (1914, 4 Haziran). Sebîlürreşâd, 12(299), 243.

S. M. Tevfik. (1912, 8 Ağustos). Mekâtîb: Hindistan muhâbir-i mahsûsamızdan: Hind yolunda 2. Sebîlürreşâd, , 8(205), 446-448.

S. M. Tevfik. (1913, 5 Haziran). Mekâtîb: Hindistan muhâbir-i mahsûsamızdan: Hind yolunda 33. Sebîlürreşâd, 10(247), 218-219.

S. M. Tevfik. (1913, 24 Temmuz). Hindistan mektupları: Bombay - Küçük Londra Sebîlürreşâd, 10(254), 327-330.

S. M. Tevfik. (1913, 8 Aralık). Mekâtîb: Hindistan muhâbir-i mahsûsamızdan: Seylan adası. Sebîlürreşâd, 11(275), 233-235.

S. M. Tevfik. (1914, 26 Mart). Mekâtîb: Hindistan muhâbir-i mahsûsamızdan: Bengale eyaleti: Sâbık Hindistan makarr-1 hükümeti. Sebîlürreşâd, 12(289), 52-53.

S. M. Tevfik. (1914, 2 Nisan). Mekâtîb: Hindistan muhâbir-i mahsûsamızdan: Sâbık Hindistan makarr-1 hükümeti. Sebîlürreşâd, 12(290), 71-72.

S. M. Tevfik. (1914, 21 Mayıs). Mekâtîb: Hindistan muhâbir-i mahsûsamızdan: Hindistan'da tıbb-1 kadîm-i Yunanî. Sebîlürreşâd, 12(297), 204-205. 
S. M. Tevfik. (1914, 28 Mayıs). Mekâtîb: Hindistan Muhâbir-i Mahsûsamızdan: Hindistan'da İslam Moğolların Âsârı. Sebîlürreşâd, 12(298), 224-225.

S. M. Tevfik. (1914, 18 Haziran). Hindistan Mektupları: Moğol imparatorlarının âsar-1 ber-güzîdeleri. Sebîlünnecât, 12(301/2), 273.

S. M. Tevfik. (1914, 25 Haziran). Hindistan mektupları: Moğol imparatorlarının âsar-1 ber-güzîdeleri: Delhi'deki müze muhteviyat1. Sebîlürreşâd, 25 Haziran 1914, 12(302), 288-290.

S. M. Tevfik. (1918, 5 Eylül). İttihâd-1 İslâm tarafdârına. Sebîlürreşâd, 15(368), 69-71.

S. M. Tevfik. (1927). Fihrist-i kütüphane-i hususi. İstanbul: Marifet Matbaas1.

Sebîlürreşâd İdare ve Kütüphanesi. (1913, 10 Nisan). Sebîlürreşâd, 10(239), 88.

Sebîlürreşâd'ın Yeni ve Mühim Bir Teşebbüsü: İslâm Memleketlerine Muhbirler İ'zâmı. (1912, 4 Temmuz). Sebîlürreşâd, 8(200), 334-335.

Sebîlürreşâd. (1912, 3 Ekim). Sebîlürreşâd, 9(213), 92. 
Bir Gazetecinin 'Muhibbân-1 Kütüp' Olarak Portresi ve S. M. Tevfik Kütüphanesi

\section{Ek. Fihrist-i Kütüphane-i Hususi: Kapak, Önsöz(ler) ve Örnek Sayfalar}

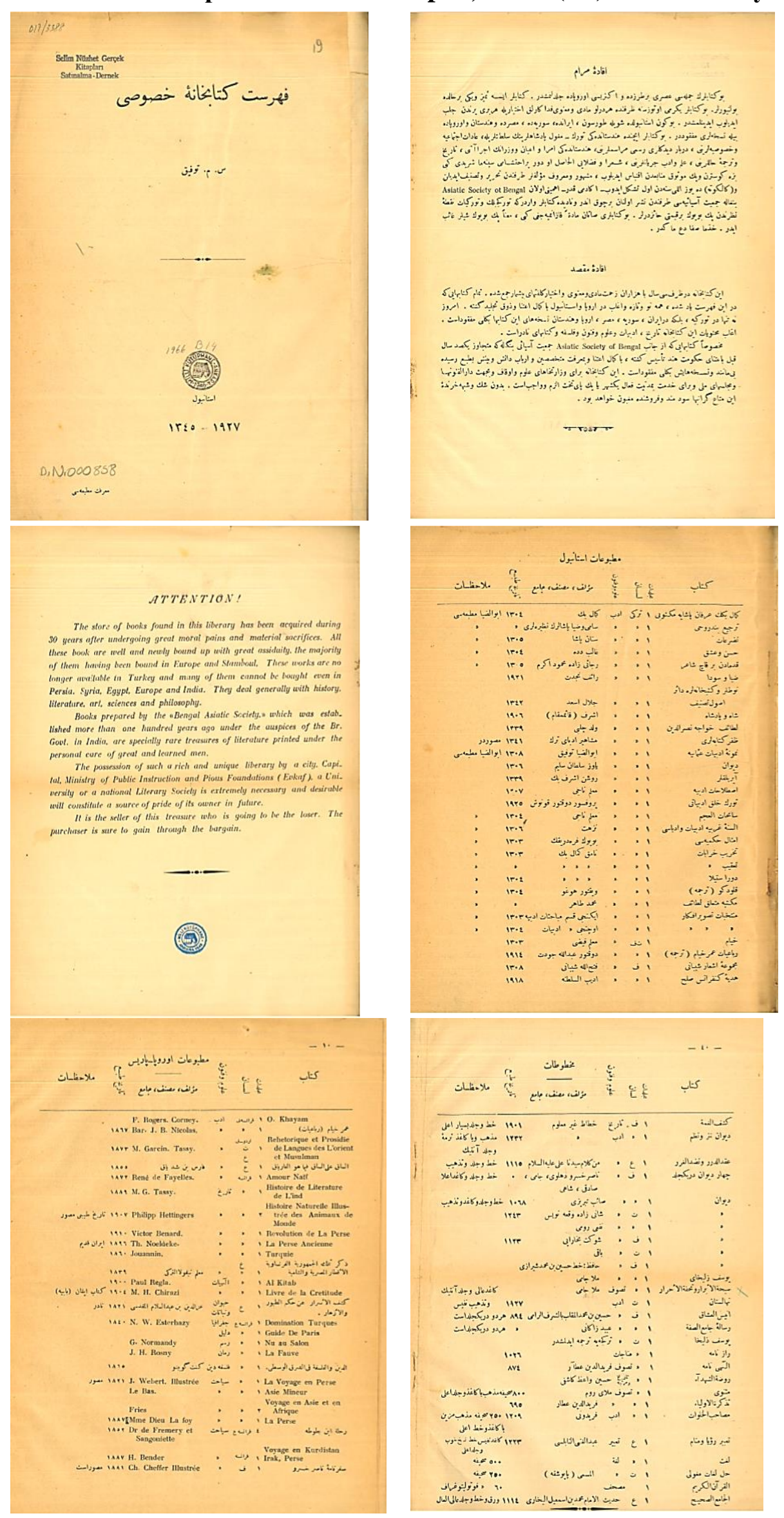




\section{Summary}

Although the II. Constitutional Era has been examined with a fine-tooth comb by various studies in terms of politics, military and economy as well as cultural history, when it comes to book and library culture, it was a period that was satisfied to focus mainly on the analysis of physical details and quantity in the context of manuscripts -printed books or reading- writing issues. Although it is methodologically correct and functional to make use of various official and statistical records to evaluate the book and library culture of any period, it will not be sufficient alone, for example, when it concerns carrying comprehensive analyses about the content of circulating books and the reader profile of that time. Indeed, it is rather important in understanding what kind of socio-cultural atmosphere the common reader profile/s other than Mecânîn-i Kütüp (incorrigible bookworms) who devoted their lives to searching for quality books with both artistic characteristics as well as contents as a necessary tradition of Mecânîni Kütüp during that period.

Sebîlürreşâd journal which started to be published during the II. Constitutional Era is among periodicals that can give an idea about the content of the books in circulation and reader profiles outside the tradition of Mecânîn-i Kütüp and Muhibbân-1 Kütüp (booklovers). Considering its corporate identity and its authors who are a part of this identity, Sebîlürreşâd journal brought together various names that were part of a generation that contributed to the book and library culture during the II. Constitutional Era. In this context, S. M. Tawfiq who is one of the names that were a part of the staff of Sebîürreşâd at some time of their lives to deserve the title of Muhibbân-1 Kütüp who have been forgotten or are unknown and somehow were involved in the missing links of the history of Turkish books and libraries is also known for his travel articles. No comprehensive study about the life of Tevik Bey who used the

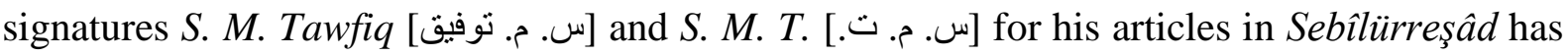
been carried about. The full name of S. M. Tawfiq, who was born in India as the child of a father from Isfahan and an Iraqi mother, grew up in Istanbul in the last quarter of the 19th century, probably in the early 1880s, and was an Ottoman subject because of his mother in spite of his Iranian father. In 1912 was published as "Sayyid Muhammad Tawfiq" in Sebîlürreşâd journal as a member of staff. Tawfiq Bey, often referred to as Sayyid Muhammad Tawfiq Hamadanî in Persian literature due to his father's origin, is also an important journalist in the modern age history of Iran, as one of the prominent figures of the constitutional movement (1905-1907), which became active in Iran in the early 1900s.

Tawfiq Bey, who was a member of the Iranian diaspora in Istanbul, who gave the most effective and strong support to the constitutionalist movement in Iran at the beginning of the 20th century, was a writer, editor, and editor-in-chief of Farsi newspapers such as Şems, Surûş and Haver published in Istanbul during this period and was among the most important names of the Iranian press during the II. Constitutional Period. Tawfiq Bey, who wrote articles in other newspapers and magazines of the period such as Şehbâl, Cerîde-i Sûfiyye, and el-Hilâl, also served as the administrator of the Iranian School (Debistân-ı Iranian) in Istanbul. Among the Iranians living in Istanbul, Tawfiq Bey is included among the names carrying the title of Muhibbân-1 Kütüp in the II. Constitutional Era and is also mentioned among the most important book collectors of the Modern Age Iranian history for dedicating his life to books, his rich library, and his expertise in books. 
The famous library of Sayyid Muhammad Tawfiq Hamadanî consists of two separate periods. The period when Tawfiq Bey, who lost a large part of his first library during a fire and started to collect books after the big fire to establish his second library corresponds to his years with Sebiliürreşâd journal, which was a part of the Ottoman press history. Therefore, it is believed that Tawfiq Bey, who explained that he spared no material and moral sacrifices to deliver/have books delivered from the countries and cities in which they were printed, made such a sacrifice by traveling as a journalist for Sebîlürreşâd journal to South Asia. Tawfiq Bey also prepared a separate "fihrist" and published it as an independent book in order to be able to save at least the copyright pages of this library - from similar destruction - that reduced the first library to ashes in the big fire that took place in 1909. Tawfiq Bey wrote a foreword in Ottoman calligraphy in Turkish and Persian for the index, which was published in 1927 under the name of "Fihrist-i Kütüphane-i Hususi" and also repeated the issues he mentioned in the foreword in English at the end of the index. He wrote his multilingual preface in a very sincere style, which can be considered as an original adaptation of "kebîkec" (a magic word which is believed to protect handwritten manuscripts from moths) in a mindset with the aesthetic and artistic depth of a book lover.

Research on the life of Tawfiq Bey who spoke Farsi, Turkish, Arabic, Hindi and English when he was alive and whose versatile accumulation is so far mentioned only by Sasanî, said that 'his good looks were like those of the Zengi, he was as industrious as a Turk, his temperament was the like of Turkish born Greeks, and his word was Indian after the proclamation of the Republic is continuing. As a part of these studies, the story of Sayyid Muhammad Tawfiq Hamadanî's life in the Ottoman book and library culture deals with the adventure and the love of books during the II. Constitutional Era has brought together the sections of the daily life of Tawfiq Bey and presents a portrait that depicts his multiple interests and abilities. This study has briefly touched the identities of Sayyid Muhammad Tawfiq Hamadanî which nourished each other and each of which were above the average of the period he lived in, and his library was included in the center in the context of his contribution to the culture of books and libraries as a book lover. It is hoped that although the article has somehow been broken or detached from the S. M. Tawfiq collection in the past, it has managed to maintain its physical presence somehow throughout the century, and will serve in discovering some books of unknown origin and finding the book legacy of the versatile S. M. Tawfiq who

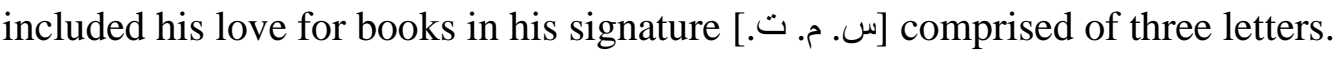

